(1)

CrossMark

\title{
Exhaled air dispersion during high-flow nasal cannula therapy versus CPAP via different masks
}

\author{
David S. Hui ${ }^{1,2}$, Benny K. Chow ${ }^{2}$, Thomas Lo ${ }^{3}$, Owen T.Y. Tsang ${ }^{4}$, Fanny W. Ko ${ }^{1}$, \\ Susanna S. $\mathrm{Ng}^{1}$, Tony Gin $\mathbb{1}^{3}$ and Matthew T.V. Chan ${ }^{3,5}$ \\ Affiliations: ${ }^{1}$ Dept of Medicine and Therapeutics, The Chinese University of Hong Kong. Shatin, Hong Kong \\ SAR, China. ${ }^{2}$ Stanley Ho Center for Emerging Infectious Diseases, The Chinese University of Hong Kong, \\ Shatin, Hong Kong SAR, China. ${ }^{3}$ Dept of Anaesthesia and Intensive Care, The Chinese University of Hong \\ Kong, Shatin, Hong Kong SAR, China. ' $D e p t$ of Medicine, Princess Margaret Hospital, Hong Kong, Hong Kong \\ SAR, China. ${ }^{5} \mathrm{Li}$ Ka Shing Institute of Health Sciences, The Chinese University of Hong Kong, Shatin, Hong \\ Kong SAR, China.
}

Correspondence: David S. Hui, Dept of Medicine and Therapeutics, The Chinese University of Hong Kong, Prince of Wales Hospital, 30-32 Ngan Shing Street, Shatin, NT, Hong Kong SAR, China. E-mail: dschuidacuhk.edu.hk

@ERSpublications

Exhaled air dispersion from high-flow nasal cannula (HFNC) and CPAP is limited provided there is good mask interface fitting. However, exhaled air leakage to $620 \mathrm{~mm}$ laterally occurs when the connection between HFNC and the interface tube becomes loose. http://ow.ly/lqEF30nqjq6

Cite this article as: Hui DS, Chow BK, Lo T, et al. Exhaled air dispersion during high-flow nasal cannula therapy versus CPAP via different masks. Eur Respir J 2019; 53: 1802339 [https://doi.org/10.1183/ 13993003.02339-2018].

\section{ABSTRACT}

Background: High-flow nasal cannula (HFNC) is an emerging therapy for respiratory failure but the extent of exhaled air dispersion during treatment is unknown. We examined exhaled air dispersion during HFNC therapy versus continuous positive airway pressure (CPAP) on a human patient simulator (HPS) in an isolation room with 16 air changes $\cdot h^{-1}$.

Methods: The HPS was programmed to represent different severity of lung injury. CPAP was delivered at 5-20 $\mathrm{cmH}_{2} \mathrm{O}$ via nasal pillows (Respironics Nuance Pro Gel or ResMed Swift FX) or an oronasal mask (ResMed Quattro Air). HFNC, humidified to $37^{\circ} \mathrm{C}$, was delivered at $10-60 \mathrm{~L} \cdot \mathrm{min}^{-1}$ to the HPS. Exhaled airflow was marked with intrapulmonary smoke for visualisation and revealed by laser light-sheet. Normalised exhaled air concentration was estimated from the light scattered by the smoke particles. Significant exposure was defined when there was $\geqslant 20 \%$ normalised smoke concentration.

Results: In the normal lung condition, mean \pm SD exhaled air dispersion, along the sagittal plane, increased from $186 \pm 34$ to $264 \pm 27 \mathrm{~mm}$ and from $207 \pm 11$ to $332 \pm 34 \mathrm{~mm}$ when CPAP was increased from 5 to $20 \mathrm{cmH}_{2} \mathrm{O}$ via Respironics and ResMed nasal pillows, respectively. Leakage from the oronasal mask was negligible. Mean \pm SD exhaled air distances increased from $65 \pm 15$ to $172 \pm 33 \mathrm{~mm}$ when HFNC was increased from 10 to $60 \mathrm{~L} \cdot \mathrm{min}^{-1}$. Air leakage to $620 \mathrm{~mm}$ occurred laterally when HFNC and the interface tube became loose.

Conclusion: Exhaled air dispersion during HFNC and CPAP via different interfaces is limited provided there is good mask interface fitting. 


\section{Introduction}

Severe acute respiratory tract infections (SARIs), such as severe acute respiratory syndrome coronavirus (SARS-CoV) infection [1], Middle East respiratory syndrome CoV (MERS-CoV) infection [2], and avian influenza $\mathrm{A}(\mathrm{H} 7 \mathrm{~N} 9)$ and $\mathrm{A}(\mathrm{H} 5 \mathrm{~N} 1)$, may lead to respiratory failure with high case fatality rates [3-5]. Oxygen therapy via conventional nasal cannula or face masks is important for managing respiratory failure during the early phase, while noninvasive ventilation (NIV) or invasive mechanical ventilation is required for the more severe cases [1-6]. However, these procedures may generate respiratory droplets [7-9] and have led to nosocomial outbreaks of SARS $[10,11]$. A systematic review has identified tracheotomy, tracheal intubation, manual ventilation and NIV as risk factors for nosocomial transmission of SARS-CoV to healthcare workers [10]. Another study has shown that performance of resuscitation, bed separation distance $<1 \mathrm{~m}$, staff members working despite having symptoms, NIV and oxygen therapy $\geqslant 6 \mathrm{~L} \cdot \mathrm{min}^{-1}$ were independent risk factors associated with super-spreading events of SARS-CoV infection [11]. Some of these risk factors were implicated in the nosocomial outbreaks of MERS-CoV infection [12]

In recent years, high-flow nasal cannula (HFNC) therapy has emerged as a therapeutic modality for acute hypoxaemic respiratory failure [13]. HFNC delivers heated humidified oxygen through short nasal prongs and supplies much higher flow rates than traditional nasal cannula systems $[13,14]$. The higher flow rate matches the patient's demand, reduces anatomical dead space by decreasing the extent of rebreathing and provides a positive pressure in the upper airway [15]. In patients with acute hypoxaemic respiratory failure, HFNC reduced inspiratory effort, and improved oxygenation and dynamic compliance [16]. HFNC reduced carbon dioxide tension in patients with stable hypercapnic chronic obstructive pulmonary disease (COPD), and the effect was flow- and leakage-dependent through airway washout and reduction of functional dead space [17]. In patients with COPD recovering from an episode of acute hypercapnic respiratory failure of various aetiologies, HFNC significantly decreased the neuroventilatory drive and work of breathing in comparison with conventional oxygen therapy after tracheal extubation [18]. Likewise, continuous positive airway pressure (CPAP) has been widely applied for treating hypoxaemia due to acute pulmonary oedema and prevention of atelectasis following abdominal surgery [19].

Although patients with SARI requiring respiratory support should preferably be managed in negative pressure isolation rooms for infection control purpose, patients with early respiratory distress are increasingly being treated with HFNC or CPAP in the intensive care unit, general ward and emergency room [20]. From the infection control point of view, it is important to understand the exhaled air dispersion distance and direction during application of HFNC and CPAP at different airflow rates, as operation of these respiratory therapies at high flow rates may potentially generate a large amount of aerosols. Unusual presentations of MERS-CoV infection in patients with renal or cardiac failure have been missed, leading to a major nosocomial outbreak [21], and the use of respiratory therapy may increase the risk of nosocomial transmission [12]. Such information would provide useful guidance for preventing nosocomial outbreaks when applying these treatment modalities in patients with respiratory failure due to SARI.

\section{Methods}

This study examined the exhaled air dispersion and directions in a hospital isolation room with dimensions of $4.1 \times 5.1 \times 2.6 \mathrm{~m}$, negative pressure of $-7.4 \mathrm{~Pa}$ and 16 air changes $\mathrm{h}^{-1}(\mathrm{ACH})$ during 1$)$ application of HFNC (Airvo 2; Fisher \& Paykel, Auckland, New Zealand) on a high-fidelity human patient simulator (HPS 6.1; Medical Education Technologies, Sarasota, FL, USA) at different oxygen flow rates (10-60 L.min $\left.{ }^{-1}\right)$ and 2) application of $\mathrm{CPAP}\left(5-20 \mathrm{cmH}_{2} \mathrm{O}\right)$ via two nasal pillows (Nuance Pro Gel; Respironics, Pittsburgh, PA, USA and Swift FX; ResMed, San Diego, CA, USA) or an orofacial mask (Quattro Air; ResMed) on the HPS (figure 1).

Our research group has published a series of field infection control experiments using the HPS to quantitatively display exhaled air dispersion (with smoke particles as marker) using a well-established laser smoke visualisation technique during application of common respiratory therapies on the medical ward and in hospital isolation rooms with negative pressure created by downward ventilation and floor-level exhausts [22-30].

The HPS contains a realistic airway and a lung model that has been applied in our previous studies to simulate human respiration [22-30]. The HPS represents a $70 \mathrm{~kg}$ adult male sitting on a $45^{\circ}$ inclined hospital bed. It can be programmed to breathe spontaneously to mimic different severity of lung injury by adjusting the oxygen consumption and lung compliance (table 1).

Exhaled air dispersion distances from the HPS during application of HFNC at 10, 30 and $60 \mathrm{~L} \cdot \mathrm{min}^{-1}$ of oxygen humidified to $37^{\circ} \mathrm{C}$ were captured using the established laser smoke visualisation method [22-30]. Exhaled air dispersion during application of CPAP at 5, 10, 15 and $20 \mathrm{cmH}_{2} \mathrm{O}$ on the HPS via the Quattro Air oronasal mask and nasal pillows was captured using the same method. 


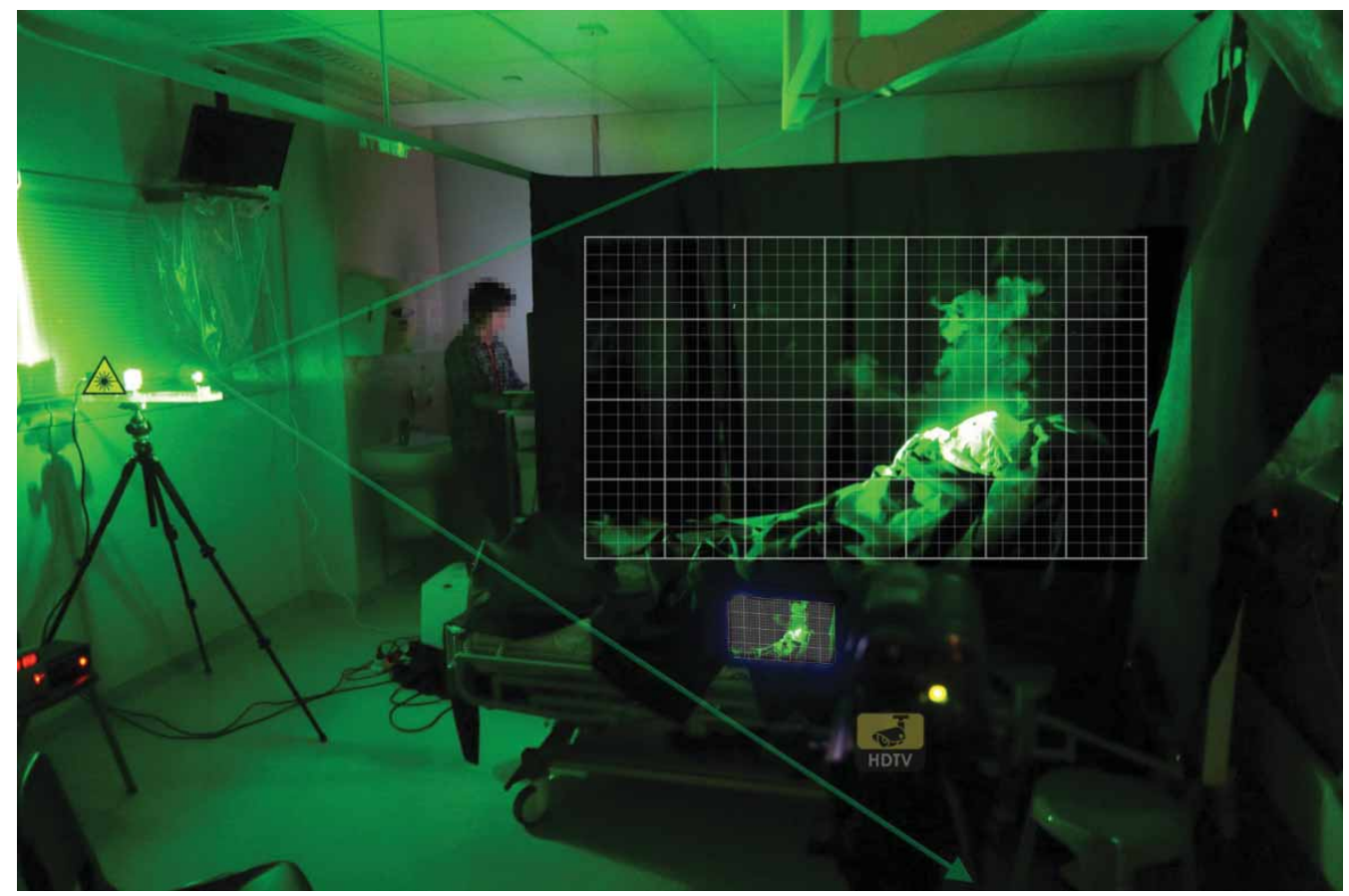

FIGURE 1 Setting of the isolation room in relation to the laser device and the video camera. The light-sheet was initially positioned in the median sagittal plane of the human patient simulator (HPS) and subsequently shifted to the paramedian planes. This would allow investigation of exhaled air in the regions directly above and lateral to the mask of the HPS [22-30]. All leakage jet plume images revealed by the laser light-sheet were captured by a high-definition digital video camera (HDR-SR8E with ClearVid complementary metal oxide semiconductor sensor and Carl Zeiss Vario-Sonnar T* lens; Sony, Tokyo, Japan), with optical resolution of $1440 \times 1080$ pixels per video frame.

\section{Flow visualisation}

Visualisation of airflow around the HPS was facilitated by marking air with smoke particles produced by a M-6000 smoke generator (N19; DS Electronics, Sydney, Australia) as previously described [22-30]. The oil-based smoke particles, measuring $<1 \mu \mathrm{m}$ in diameter, are known to follow the airflow pattern with negligible slip [31]. The smoke was introduced to the right main bronchus of the HPS. It mixed with alveolar gas and was then exhaled through the airway. Sections through the leakage jet plume were then revealed by a thin green laser light-sheet ( $532 \mathrm{~nm}$ wavelength, continuous wave mode) generated by a diode-pumped solid-state laser (OEM UGH-800 mW; Lambdapro Technologies, Shanghai, China), with custom cylindrical optics [22-30].

\section{Image analysis}

As the smoke particles marked exhaled air that came out from the lower airways of the HPS before leaking from the mask, the concentration contours effectively represented the probability of encountering air around the patient that had come from within the mask and/or the patient's respiratory system. A contour value of 1 indicated a region that consisted entirely of air exhaled by the patient, where there was a very

\begin{tabular}{|c|c|c|c|}
\hline & Normal lung condition & Mild lung injury & Severe lung injury \\
\hline Oxygen consumption $\mathrm{mL} \cdot \mathrm{min}^{-1}$ & 200 & 300 & 500 \\
\hline Lung compliance $\mathrm{mL} \cdot \mathrm{cmH}_{2} \mathrm{O}^{-1}$ & 70 & 35 & 10 \\
\hline Respiratory rate ${ }^{\#}$ breaths $\cdot \min ^{-1}$ & 12 & 25 & 40 \\
\hline Tidal volume ${ }^{\#} \mathrm{~mL}$ & 700 & 300 & 150 \\
\hline
\end{tabular}

\#: the respiratory rate and tidal volume were adjusted by the HPS to achieve primarily the target oxygen consumption and lung compliance. 
high chance of exposure to the exhaled air. A contour value near 0 indicated a region with no measurable exhaled smoke particles, where there was a small chance of exposure to the exhaled air. Significant exposure was arbitrarily defined as where there was $\geqslant 20 \%$ normalised smoke concentration [22-30]. More technical details of image analysis and extraction are provided in the supplementary material.

\section{Statistical analysis}

The dispersion distances were expressed as mean with standard deviation. A generalised linear model was used to estimate the difference in exhaled air dispersion after application of HFNC adjusting for airflow rates and extent of lung injury (normal versus mild or severe). A similar model was created for studying exhaled air dispersion with CPAP therapy, adjusted for CPAP applied, severity of lung injury and type of mask. A p-value $<0.05$ was considered as statistically significant. The study received nonionising radiation safety approval (N/DSCH/HMRF2015) from the Chinese University of Hong Kong (Shatin, Hong Kong SAR, China).

\section{Results}

\section{High-flow nasal cannula}

When the HPS was programmed in the normal lung condition and humidified air was delivered to the HPS, the exhaled air dispersion distances from HFNC along the median sagittal plane above the nostrils increased significantly with increasing flow rate to a mean \pm SD maximum of $172 \pm 33 \mathrm{~mm} \quad(\mathrm{p}<0.001)$ (figure 2 and table 2). With worsening severity of lung injury, the exhaled air distances from the HPS decreased significantly $(\mathrm{p}<0.001)$. An interaction term of severity of lung injury $\times$ flow rates affected exhaled air dispersion significantly $(\mathrm{p}<0.001)$.
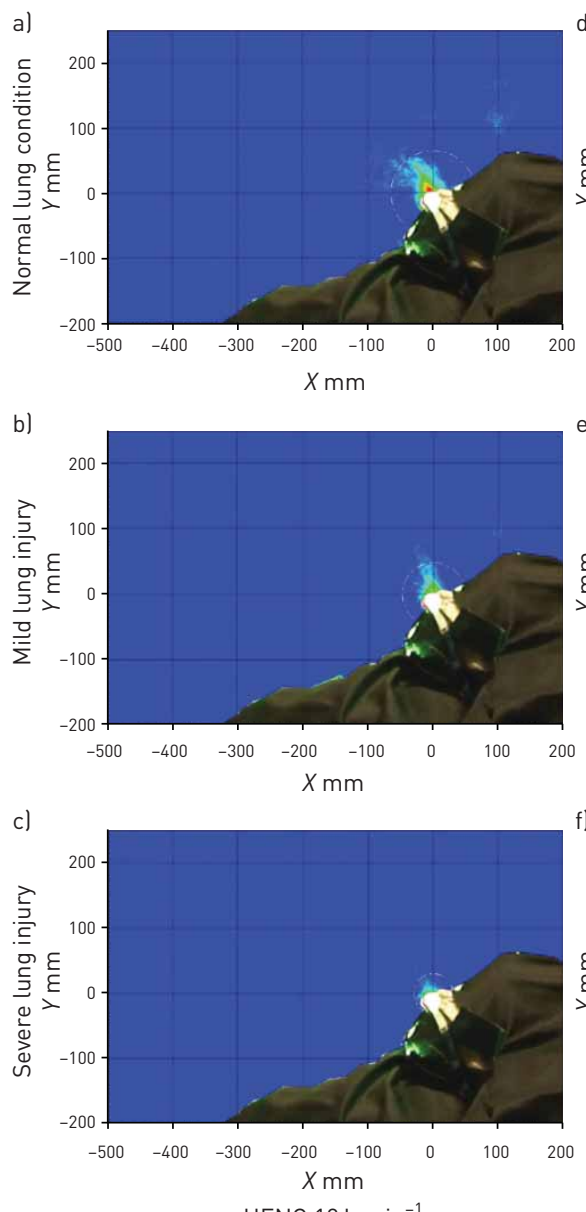

HFNC $10 \mathrm{~L} \cdot \mathrm{min}^{-1}$
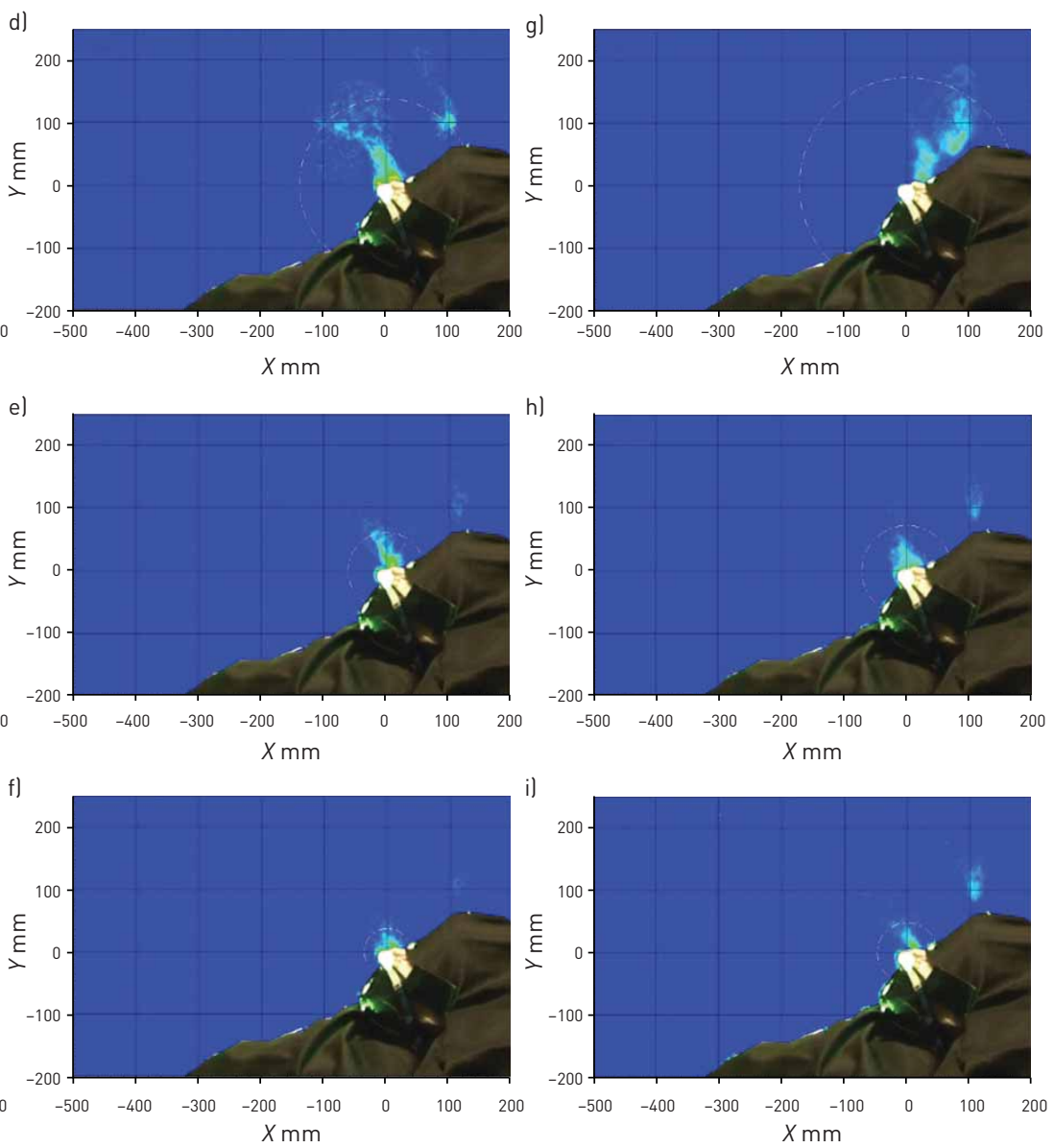

HFNC $30 \mathrm{~L} \cdot \mathrm{min}^{-1}$

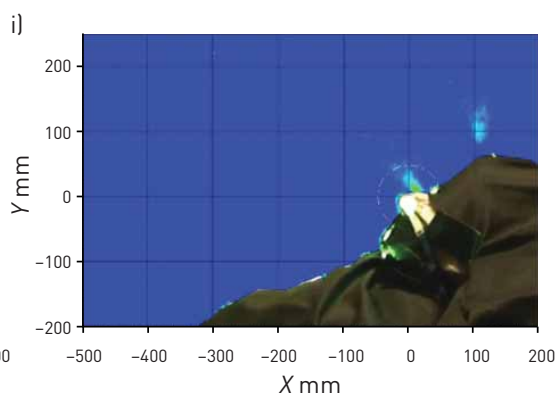

HFNC $60 \mathrm{~L} \cdot \mathrm{min}^{-1}$

FIGURE 2 Graphic coloured images of exhaled air leakage during application of high-flow nasal cannula (HFNC) at 10,30 and $60 \mathrm{~L} \cdot \mathrm{min}^{-1}$ on the human patient simulator lying at $45^{\circ}$ on the bed programmed at different severity of lung injury (normal lung condition, mild lung injury and severe lung injury). The coloured key indicates the contour values of the normalised concentration of smoke particles (see the Image analysis section for details). 
TABLE 2 Exhaled air dispersion with 20\% normalised smoke concentration during application of high-flow nasal cannula at $37^{\circ} \mathrm{C}$ under different severity of lung injury

\begin{tabular}{lccc} 
Scenario & Lung condition/injury & Flow rate L. $\mathbf{m i n}^{\mathbf{- 1}}$ & Exhaled air dispersion distance $\mathbf{m m}$ \\
\hline $\mathbf{1}$ & Normal & 60 & $172 \pm 33$ \\
$\mathbf{2}$ & Mild & 60 & $72 \pm 18$ \\
$\mathbf{3}$ & Severe & 60 & $48 \pm 16$ \\
$\mathbf{4}$ & Normal & 30 & $130 \pm 11$ \\
$\mathbf{5}$ & Mild & 30 & $61 \pm 17$ \\
$\mathbf{6}$ & Severe & 30 & $37 \pm 12$ \\
$\mathbf{7}$ & Normal & 10 & $65 \pm 15$ \\
$\mathbf{8}$ & Mild & 10 & $43 \pm 10$ \\
$\mathbf{9}$ & Severe & 10 & $30 \pm 8$ \\
\hline
\end{tabular}

Data are presented as $n$ or mean \pm SD.

There was negligible lateral dispersion of exhaled air when the nasal cannula was tightly connected to the tubing. However, exhaled air dispersion extended to $620 \mathrm{~mm}$ laterally with a loose connection between the cannula and the interface tube when HFNC at $60 \mathrm{~L} \cdot \mathrm{min}^{-1}$ was delivered to the HPS programmed in the normal lung condition (figure 3).

\section{Continuous positive airway pressure}

Quattro air mask

There was no significant leakage from the Quattro Air mask when CPAP was applied at 5, 10, 15 or $20 \mathrm{cmH}_{2} \mathrm{O}$. Exhaled air dispersed evenly via the vent holes located circularly around the elbow connection point in all directions at very low normalised smoke concentration $<20 \%$. Thus, there was no distinct exhaled air dispersion that could be measured (supplementary figure S2).

\section{Nasal pillows}

Figures 4-6 show the exhaled air dispersion from the Nuance Pro Gel and Swift FX nasal pillows at varying severity of lung injury. There was a significant increase in exhaled air dispersion distance for both nasal pillows with increasing CPAP $(\mathrm{p}<0.001)$. Worsening severity of lung injury also reduced dispersion $(\mathrm{p}<0.001)$. There was, however, no difference in exhaled air dispersion between the two types of nasal pillows $(\mathrm{p}=0.095)$. An interaction term of severity of lung injury $\times$ CPAP affected exhaled air dispersion significantly $(\mathrm{p}<0.001)$ (table 3 and supplementary figure $\mathrm{S} 3$ ).

\section{Discussion}

This infection control study has demonstrated mean \pm SD exhaled air dispersion up to $172 \pm 33 \mathrm{~mm}$ along the sagittal plane via HFNC at $60 \mathrm{~L} \cdot \mathrm{min}^{-1}$. When CPAP was increased from 5 to $20 \mathrm{cmH}_{2} \mathrm{O}$ via the Nuance Pro Gel and Swift FX nasal pillows, similar leakage distances could be detected up to 264 and $332 \mathrm{~mm}$, respectively. As the severity of lung injury worsened, the exhaled air dispersion distances became
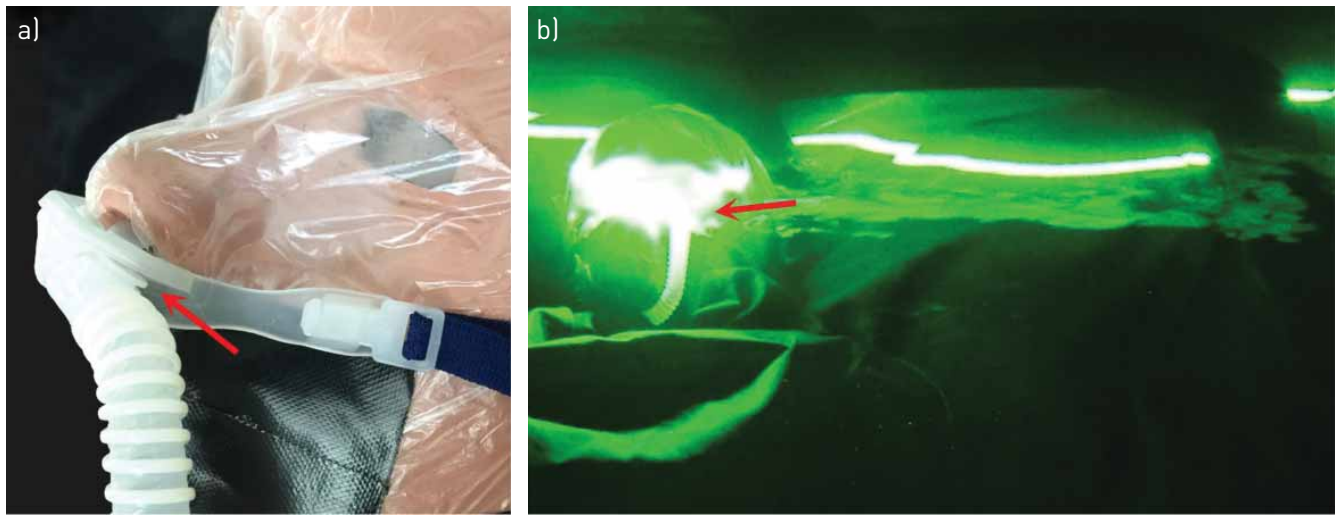

FIGURE 3 a) A loose connection (arrow) between the high-flow nasal cannula $\left(60 \mathrm{~L} \cdot \mathrm{min}^{-1}\right.$ ) and the interface tube. b) This resulted in exhaled air leakage to $620 \mathrm{~mm}$ laterally. 

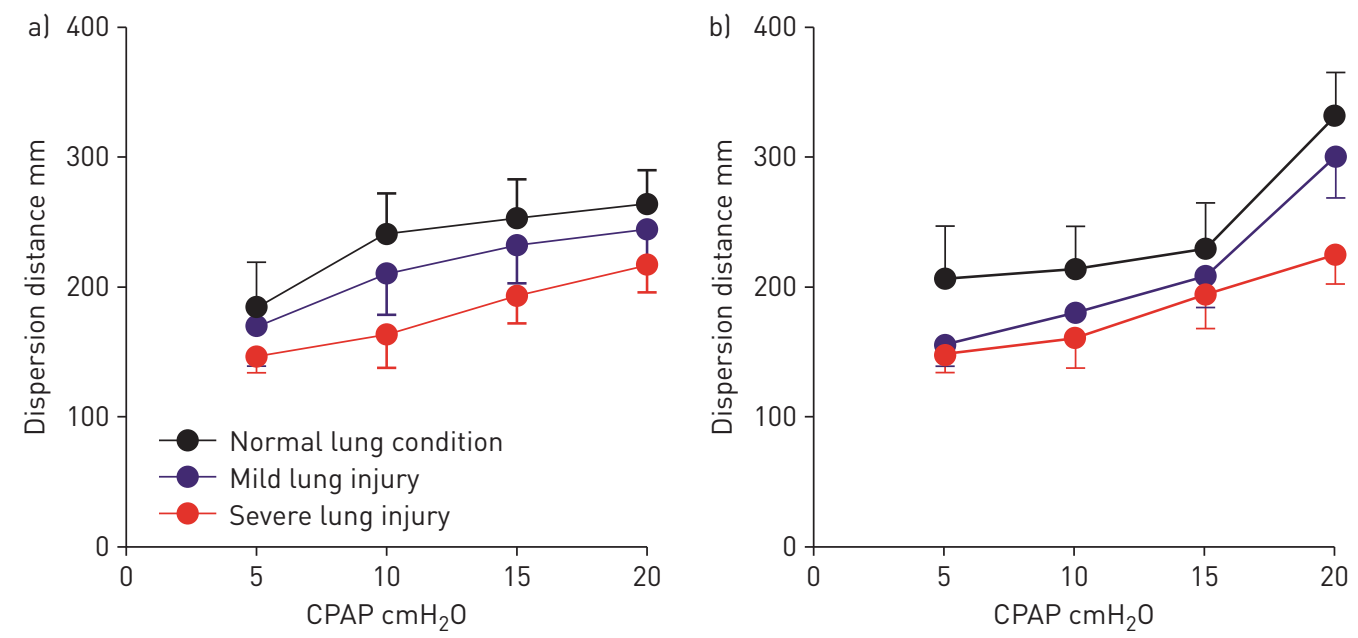

FIGURE 4 Changes of exhaled air dispersion with increasing continuous positive airway pressure (CPAP) and worsening degree of lung injury in al Respironics Nuance Pro Gel and b) ResMed Swift FX nasal pillows.

shorter for both HFNC and CPAP via nasal cannula. In contrast, when CPAP was increased up to $20 \mathrm{cmH}_{2} \mathrm{O}$ via the Quattro Air mask, there was no significant leakage, irrespective of the severity of lung injury.

Our findings are consistent with a study recently reported by our intensivists assessing the extent of environmental contamination in critically ill patients receiving HFNC or oxygen via a simple oxygen mask for Gram-negative bacterial pneumonia. Regardless of treatment modalities, Gram-negative bacteria could hardly be detected in the air samples or settle plates located 0.4 and $1.5 \mathrm{~m}$ from the patients managed in single isolation rooms with 6 or $12 \mathrm{ACH}$. These results suggested that HFNC did not enhance airborne and surface contamination [32].

Our data show that HFNC did not increase the spread of exhaled air despite operating at higher flow rates, likely due to the fact that the positive end-expiratory pressure (PEEP) remained low at $60 \mathrm{~L} \cdot \mathrm{min}^{-1}$. Interestingly, there was comparable spread $(186-207 \mathrm{~mm})$ when CPAP was applied at $5 \mathrm{cmH}_{2} \mathrm{O}$ to the HPS via the Nuance Pro Gel or Swift FX nasal pillows. CPAP via nasal pillows produced larger PEEP and hence exhaled air was dispersed further away. In the same isolation room setting, we have previously demonstrated that an exhalation jet spread almost horizontally outward from the nostrils of the HPS to 0.66 and $1 \mathrm{~m}$ towards the end of the bed along the sagittal plane when oxygen flow via a conventional nasal cannula was increased from 1 to $5 \mathrm{~L} \cdot \mathrm{min}^{-1}$, respectively [24]. The longer exhaled air dispersion distance from the conventional low-flow nasal cannula versus that from HFNC is likely due to the fact that the former was loosely applied on the nostrils, while HFNC and CPAP delivered via the nasal route were tightly "fitted and strapped" to the face. In addition, air humidification at $37^{\circ} \mathrm{C}$ for HFNC therapy would generate larger droplets on exhalation with a shorter trajectory path due to the effect of gravity. These results are reassuring for the use of HFNC in the high dependency unit or medical ward despite much higher flow rates. Nevertheless, it is important to ensure a tight and proper connection at the nasal cannula and tubing interface as otherwise dispersion to $620 \mathrm{~mm}$ laterally may occur, although this is well within the respiratory droplet distance of up to $1.8 \mathrm{~m} \mathrm{[33].}$

The World Health Organization guideline for infection prevention and control of epidemic- and pandemicprone acute respiratory infections in the healthcare setting has recommended droplet precautions (keeping a patient spatial separation distance of at least $1 \mathrm{~m}$ in an adequately ventilated ward if a single room is not available and healthcare workers should wear a surgical mask with eye protection within $2 \mathrm{~m}$ from the patient) and contact precautions (healthcare workers should maintain good hand hygiene and wear gloves and gowns, in addition to cleaning and disinfection of surfaces and equipment in the patient care environment). However, if the disease is caused by airborne pathogens such as tuberculosis or a novel pathogen with unknown route of transmission, then airborne precautions such as wearing N95 masks that filter at least $95 \%$ of airborne particles and a negative pressure isolation room should be implemented [34]. These principles are applicable to the use of HFNC for patients with respiratory failure due to infective aetiology.

The Quattro Air full-face mask is different from other NIV face masks with respect to the design of exhaust ventilation $[26,28]$. There are circular vent holes, evenly distributed circularly around the elbow 

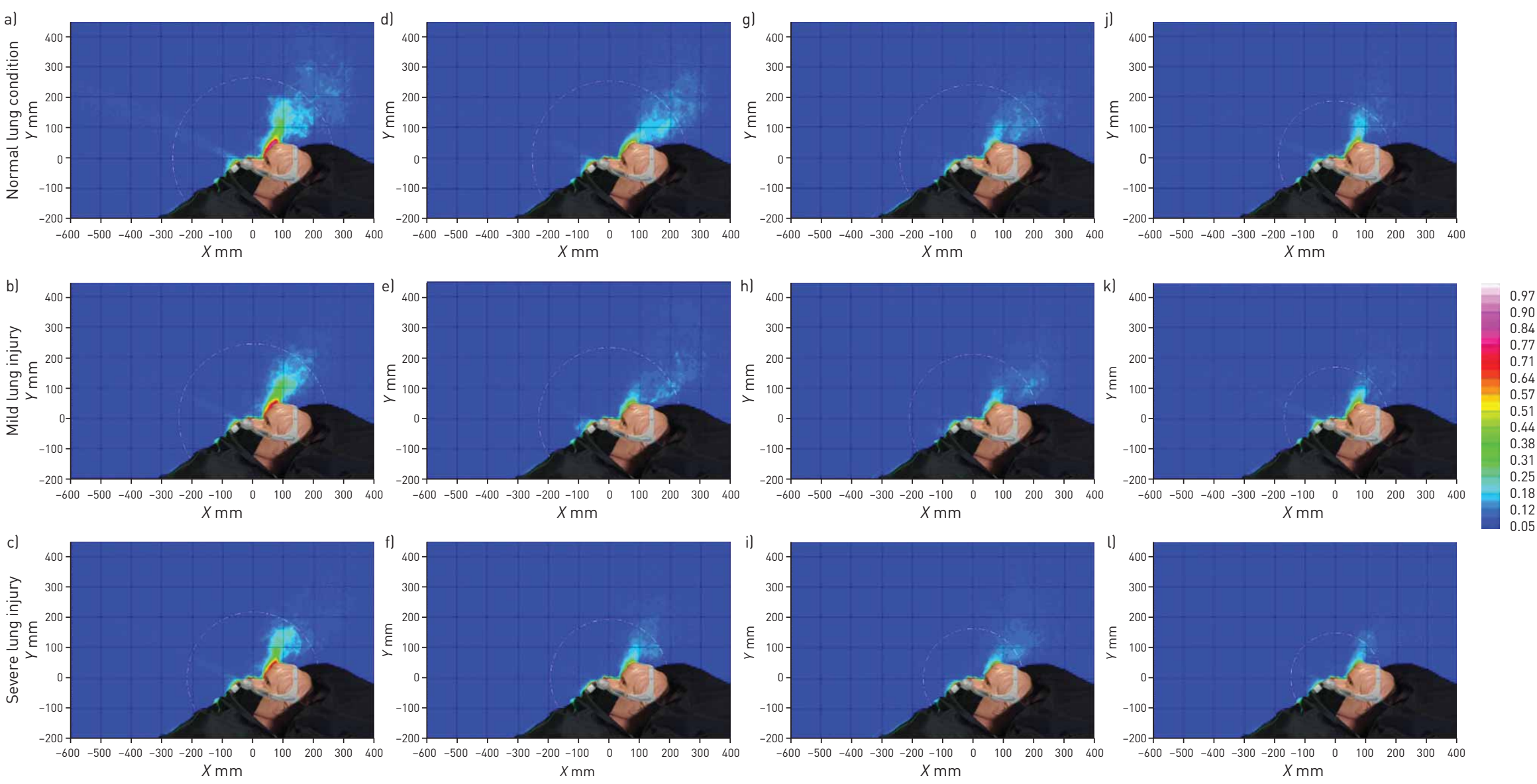

Respironics Nuance Pro Gel CPAP $20 \mathrm{cmH}_{2} \mathrm{O}$

Respironics Nuance Pro Gel CPAP $15 \mathrm{cmH}_{2} \mathrm{O}$

Respironics Nuance Pro Gel CPAP $10 \mathrm{cmH}_{2} \mathrm{O}$

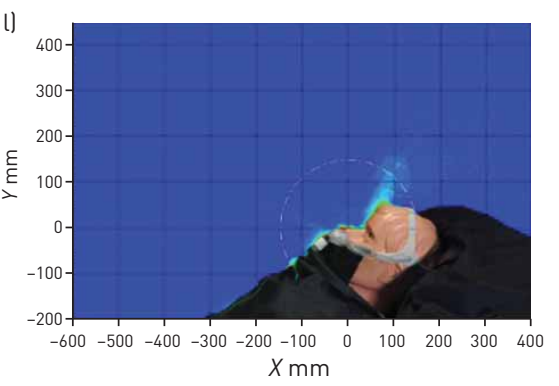

Respironics Nuance Pro Gel CPAP $5 \mathrm{cmH}_{2} \mathrm{O}$

FIGURE 5 Graphic coloured images of exhaled air during application of continuous positive airway pressure (CPAP) at $5,10,15$ or $20 \mathrm{cmH}_{2} \mathrm{O}$ via Respironics Nuance Pro Gel nasal pillows on the human patient simulator lying at $45^{\circ}$ on the bed programmed at different severity of lung injury (normal lung condition, mild lung injury and severe lung injury). The coloured key indicates the contour values of the normalised concentration of smoke particles (see the Image analysis section for details). 

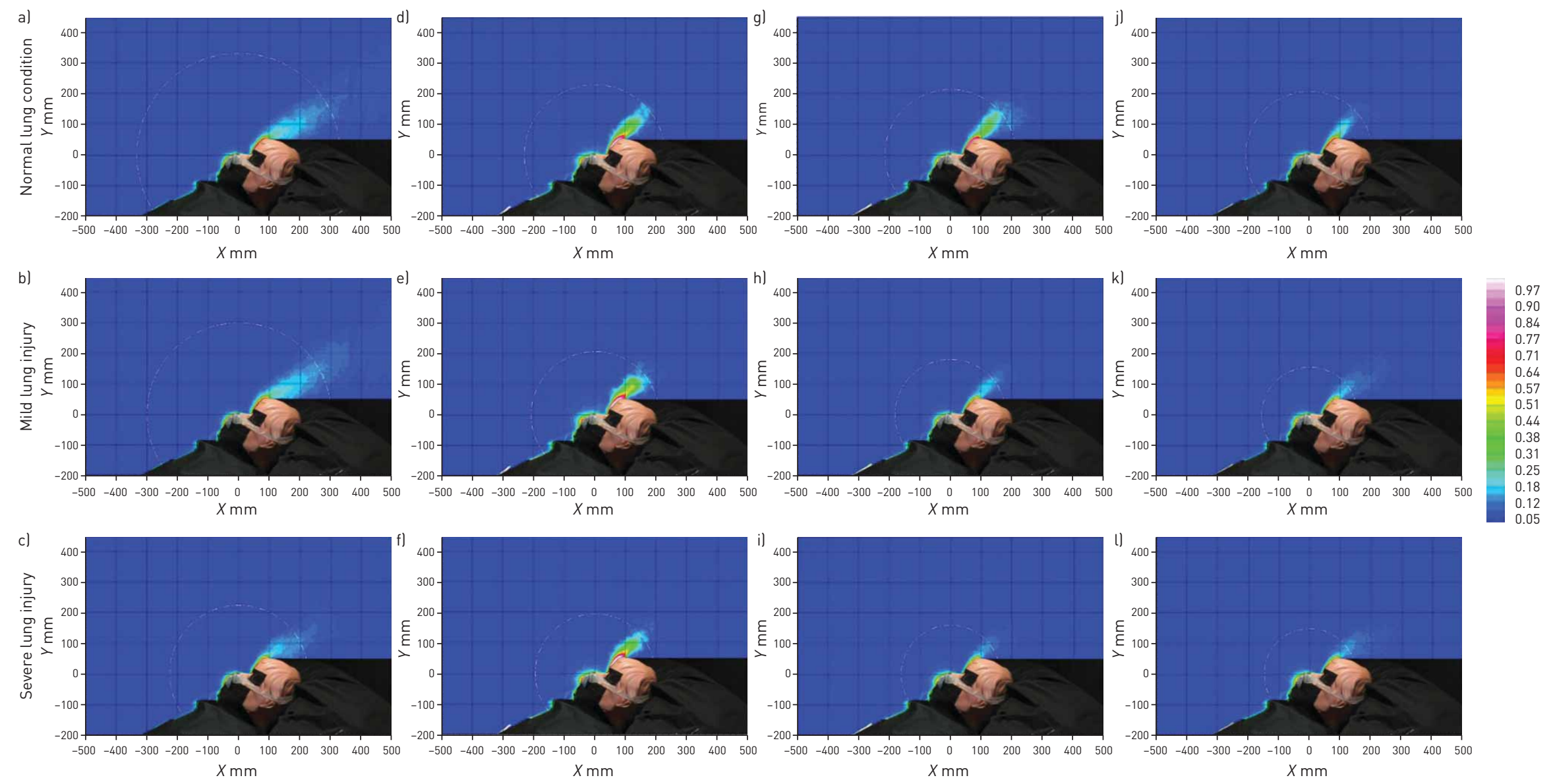

ResMed Swift FX CPAP $20 \mathrm{cmH}_{2} \mathrm{O}$

ResMed Swift FX CPAP $15 \mathrm{cmH}_{2} \mathrm{O}$

ResMed Swift FX CPAP $10 \mathrm{cmH}_{2} \mathrm{O}$

ResMed Swift FX CPAP $5 \mathrm{cmH}_{2} \mathrm{O}$

FIGURE 6 Graphic coloured images of exhaled air during application of continuous positive airway pressure (CPAP) at $5,10,15$ or $20 \mathrm{cmH} \mathrm{H}_{2} \mathrm{O}$ via ResMed Swift FX nasal pillows on the human patient simulator lying at $45^{\circ}$ on the bed programmed at different severity of lung injury (normal lung condition, mild lung injury and severe lung injury). The coloured key indicates the contour values of the normalised concentration of smoke particles (see the Image analysis section for details). 
TABLE 3 Exhaled air dispersion with 20\% normalised smoke concentration during application of continuous positive airway pressure (CPAP) via Respironics Nuance Pro Gel and ResMed Swift FX nasal pillows at different severity of lung injury

\begin{tabular}{|c|c|c|c|}
\hline \multirow[t]{2}{*}{ CPAP $\mathrm{cmH}_{2} \mathrm{O}$} & \multirow[t]{2}{*}{ Lung condition/injury } & \multicolumn{2}{|c|}{ Exhaled air dispersion distance $\mathrm{mm}$} \\
\hline & & Nuance Pro Gel & Swift FX \\
\hline \multirow[t]{3}{*}{20} & Normal & $264 \pm 27$ & $332 \pm 34$ \\
\hline & Mild & $245 \pm 26$ & $300 \pm 31$ \\
\hline & Severe & $217 \pm 21$ & $225 \pm 22$ \\
\hline \multirow[t]{3}{*}{15} & Normal & $253 \pm 30$ & $230 \pm 35$ \\
\hline & Mild & $233 \pm 29$ & $208 \pm 24$ \\
\hline & Severe & $193 \pm 21$ & $195 \pm 26$ \\
\hline \multirow[t]{3}{*}{10} & Normal & $241 \pm 30$ & $214 \pm 32$ \\
\hline & Mild & $211 \pm 32$ & $181 \pm 20$ \\
\hline & Severe & $164 \pm 26$ & $161 \pm 24$ \\
\hline \multirow[t]{3}{*}{5} & Normal & $186 \pm 34$ & $207 \pm 40$ \\
\hline & Mild & $170 \pm 30$ & $156 \pm 16$ \\
\hline & Severe & $148 \pm 14$ & $149 \pm 14$ \\
\hline
\end{tabular}

Data are presented as $\mathrm{n}$ or mean $\pm \mathrm{SD}$.

connection point of the air tubing, which allow continuous flow of air out of the mask (supplementary figure S2b). Thus, there was no distinct exhaled air jet of significant normalised concentration that could be measured during application of CPAP at different pressures via a single circuit on the HPS. In contrast, application of NIV via a single circuit and other face masks with an exhalation port, such as Mirage (ResMed) [26], and Comfortfull 2 and Image 3 (Respironics) [28], could lead to more widespread exhaled air leakage to 500, 800 and $950 \mathrm{~mm}$, respectively, especially at higher inspiratory pressures and in connection with the whisper swivel device [28]. From the infection control and prevention point of view, another safe way of applying NIV is through a helmet with a good seal at the neck interface via a double circuit [29]. Among patients with acute respiratory distress syndrome, a single-centre randomised trial has shown that treatment with helmet NIV resulted in a significant reduction of intubation rates with reduction in 90-day mortality versus NIV via a face mask [35]. Although there is a lack of data to recommend the use of NIV for pandemic viral illness, it is reasonable to provide a cautious trial in carefully selected patients with acute hypoxaemic respiratory failure in experienced centres equipped with negative pressure isolation rooms [36].

Early CPAP has been reported as a simple way to prevent deterioration of respiratory function and complications in patients with haematological malignancy [37]. However, a multicentre randomised trial of 374 immunocompromised subjects showed that early NIV was not associated with clinical benefits in terms of mortality, nosocomial infections, duration of invasive mechanical ventilation or length of intensive care unit stay versus standard oxygen therapy [38], while another more recent randomised trial has shown that HFNC did not significantly reduce 28-day mortality versus standard oxygen therapy in immunocompromised patients $(\mathrm{n}=776)$ with acute hypoxaemic respiratory failure [39]. In contrast, another randomised open-label study of 310 patients with acute hypoxaemic respiratory failure has shown that HFNC led to lower risk of tracheal intubations and 90-day mortality in comparison with NIV or standard oxygen therapy [40]. A post hoc analysis of 82 immunocompromised patients enrolled in a larger trial of patients with acute respiratory failure suggested no benefit of NIV, either for tracheal intubation or survival [41]. Currently, there is a recommendation for the use of bilevel NIV or early CPAP for immunocompromised patients with acute respiratory failure [36], but the role of HFNC in such patients deserves further evaluation given the limited dispersion of exhaled air as shown by this study, and the lack of airborne and surface contamination in the Gram-negative bacteria environmental contamination study [32].

Recently, an experimental study on healthy subjects has shown that a combination of HFNC delivering nasal high flow within a sealed helmet connected to a PEEP valve can provide a stable PEEP and effective washout of carbon dioxide from the upper airway with negligible carbon dioxide rebreathing [42]. More studies are needed to determine whether HFNC has advantages over NIV in managing different types of respiratory failure. Development of more securely fitted mask interface connections and less turbulent exhaust ventilation is needed to minimise the risk of nosocomial transmission during application of HFNC and NIV in patients with respiratory failure due to SARI.

This study is limited by the use of smoke particles as markers of exhaled air because there is no safe and reliable marker that can be introduced into human lungs for study. As the smoke particles in this study mark 
the continuous air phase, our data contours are referring to exhaled air and represent the "upper bound" estimates for the dispersion of droplets, which would be expected to follow a shorter trajectory than the exhaled air jet because of gravitational effects, but not fully reflect the risk of droplet transmission [22-30].

In summary, exhaled air dispersion distance during application of HFNC at $60 \mathrm{~L} \cdot \mathrm{min}^{-1}$ is shorter than that from application of CPAP via commonly used nasal pillows. However, leakage to $620 \mathrm{~mm}$ laterally may occur in the presence of a loose connection between the HFNC and the interface tubing. Exhaled air dispersion during application of CPAP via the Quattro Air face mask and a single circuit is a safe option for patients with respiratory infections complicated by respiratory failure due to its negligible leakage through the circular vent holes if NIV via a helmet through a double circuit is not available.

Contributor: D.S. Hui, B.K. Chow and M.T.V. Chan collaborated on study design, data acquisition and interpretation, and preparation of the manuscript. B.K. Chow performed data analysis. T. Lo, O.T.Y. Tsang, F.W. Ko, S.S. Ng and T. Gin provided technical support to this study. D.S. Hui is the guarantor of the content of the manuscript. All authors have read and approved the manuscript for submission.

Conflict of interest: None declared.

Support statement: We thank the Food and Health Bureau (Hong Kong SAR, China) for funding this study (HMRF\#15140282). The sponsor approved the study design but played no role in the development of the research and manuscript. Funding information for this article has been deposited with the Crossref Funder Registry.

\section{References}

1 Lee $\mathrm{N}$, Hui D, Wu A, et al. A major outbreak of severe acute respiratory syndrome in Hong Kong. $N$ Engl J Med 2003; 348: 1986-1994.

2 Zumla A, Hui DS, Perlman S. Middle East respiratory syndrome. Lancet 2015; 386: 995-1007.

3 Hui DS, Lee N, Chan PK. A clinical approach to the threat of emerging influenza viruses in the Asia-Pacific region. Respirology 2017; 22: 1300-1312.

4 Gao HN, Lu HZ, Cao B, et al. Clinical findings in 111 cases of influenza A (H7N9) virus infection. N Engl J Med 2013; 368: 2277-2285.

5 Writing Committee of the Second World Health Organization Consultation on Clinical Aspects of Human Infection with Avian Influenza A (H5N1) Virus. Update on avian influenza A (H5N1) virus infection in humans. N Engl J Med 2008; 358: 261-273.

6 Arabi Y, Al-Omari A, Mandourah Y, et al. Critically ill patients with the Middle East respiratory syndrome a multicenter retrospective cohort study. Crit Care Med 2017; 45: 1683-1695.

7 Qian H, Li Y, Nielsen PV, et al. Dispersion of exhalation pollutants in a two-bed hospital ward with a downward ventilation system. Build Environ 2008; 43: 344-354.

8 Tang JW, Li Y, Eames I, et al. Factors involved in the aerosol transmission of infection and control of ventilation in healthcare premises. J Hosp Infect 2006; 64: 100-114.

9 Eames I, Tang JW, Li Y, et al. Airborne transmission of disease in hospitals. J R Soc Interface 2009; 6: S697-S702.

10 Tran K, Cimon K, Severn M, et al. Aerosol generating procedures and risk of transmission of acute respiratory infections to healthcare workers: a systematic review. PLoS One 2012; 7: e35797.

11 Yu IT, Xie ZH, Tsoi KK, et al. Why did outbreaks of severe acute respiratory syndrome occur in some hospital wards but not in others? Clin Infect Dis 2007; 44: 1017-1025.

12 Hui DS, Azhar EI, Kim YJ, et al. Middle East respiratory syndrome coronavirus: risk factors and determinants of primary, household, and nosocomial transmission. Lancet Infect Dis 2018; 18: e217-e227.

13 Spoletini G, Alotaibi M, Blasi F, et al. Heated humidified high-flow nasal oxygen in adults: mechanisms of action and clinical implications. Chest 2015; 148: 253-261.

14 Frat JP, Coudroy R, Marjanovic N, et al. High-flow nasal oxygen therapy and noninvasive ventilation in the management of acute hypoxemic respiratory failure. Ann Transl Med 2017; 5: 297.

15 Moller W, Feng S, Domanski U, et al. Nasal high flow reduces dead space. J Appl Physiol 2017; 122: 191-197.

16 Mauri T, Alban L, Turrini C, et al. Optimum support by high-flow nasal cannula in acute hypoxemic respiratory failure: effects of increasing flow rates. Intensive Care Med 2017; 43: 1453-1463.

17 Braunlich J, Mauersberger F, Wirtz H. Effectiveness of nasal high flow in hypercapnic COPD patients is flow and leakage dependent. BMC Pulm Med 2018; 18: 14.

18 Di Mussi R, Spadaro S, Stripoli T, et al. High-flow nasal cannula oxygen therapy decreases postextubation neuroventilatory drive and work of breathing in patients with chronic obstructive pulmonary disease. Crit Care 2018; 22: 180.

19 Keenan SP, Sinuff T, Burns KE, et al. Clinical practice guidelines for the use of noninvasive positive-pressure ventilation and noninvasive continuous positive airway pressure in the acute care setting. CMAJ 2011; 183: E195-E214.

20 Rittayamai N, Tscheikuna J, Praphruetkit N, et al. Use of high flow nasal cannula for acute dyspnea and hypoxemia in the Emergency Department. Respir Care 2015; 60: 1377-1382.

21 Amer $\mathrm{H}$, Alqahtani AS, Alzoman $\mathrm{H}$, et al. Unusual presentation of Middle East respiratory syndrome coronavirus leading to a large outbreak in Riyadh during 2017. Am J Infect Control 2018; 46: 1022-1025.

22 Hui DS, Ip M, Tang JW, et al. Airflows around oxygen masks: a potential source of infection? Chest 2006; 130: 822-826.

23 Hui DS, Hall SD, Chan MT, et al. Exhaled air dispersion during oxygen delivery via a simple oxygen mask. Chest 2007; 132: 540-546. 
24 Hui DS, Chow BK, Chu L, et al. Exhaled air dispersion and removal is influenced by isolation room size and ventilation settings during oxygen delivery via nasal cannula. Respirology 2011; 16: 1005-1013.

25 Hui DS, Chow BK, Hall SD, et al. Exhaled air and aerosolized droplet dispersion during application of a jet nebulizer. Chest 2009; 135: 648-654.

26 Hui DS, Hall SD, Chan MT, et al. Non-invasive positive pressure ventilation: an experimental model to assess air and particle dispersion. Chest 2006; 130: 730-740.

27 Chan MT, Chow B, Chu L, et al. Mask ventilation and dispersion of exhaled air. Am J Respir Crit Care Med 2013; 187: e12-e14.

28 Hui DS, Chow BK, Hall SD, et al. Exhaled air dispersion distances during application of non-invasive ventilation via different Respironics face masks. Chest 2009; 136: 998-1005.

29 Hui DS, Chow B, Lo T, et al. Exhaled air dispersion distances during non-invasive ventilation via helmet masks and a total face mask. Chest 2015; 147: 1336-1343.

30 Chan MT, Chow BK, Lo T, et al. Exhaled air dispersion during bag-mask ventilation and sputum suctioning implications for infection control. Sci Rep 2018; 8: 198.

31 Soo SL. Fluid Dynamics of Multiphase Systems. Toronto, Blaisdell, 1967.

32 Leung CC, Joynt GM, Gomersall CD, et al. Comparison of high-flow nasal cannula versus oxygen face mask for environmental bacterial contamination in critically ill pneumonia patients: a randomized controlled crossover trial. J Hosp Infect 2019; 101: 84-87.

33 Bischoff WE, Swett K, Leng I, et al. Exposure to influenza virus aerosols during routine patient care. J Infect Dis 2013; 207: 1037-1046.

34 World Health Organization. Infection prevention and control of epidemic- and pandemic-prone acute respiratory infections in health care. 2014. http://apps.who.int/iris/bitstream/handle/10665/112656/9789241507134_eng.pdf Date last accessed: January 15, 2019.

35 Patel BK, Wolfe KS, Pohlman AS, et al. Effect of noninvasive ventilation delivered by helmet $v$ s face mask on the rate of endotracheal intubation in patients with acute respiratory distress syndrome: a randomized clinical trial. JAMA 2016; 315: 2435-2441.

36 Rochwerg B, Brochard L, Elliott MW, et al. Official ERS/ATS clinical practice guidelines: noninvasive ventilation for acute respiratory failure. Eur Respir J 2017; 50: 1602426.

37 Squadrone V, Massaia M, Bruno B, et al. Early CPAP prevents evolution of acute lung injury in patients with hematologic malignancy. Intensive Care Med 2010; 36: 1666-1674.

38 Lamiale V, Mokart D, Resche-Rigon M, et al. Effect of noninvasive ventilation vs oxygen therapy on mortality among immunocompromised patients with acute respiratory failure: a randomized clinical trial. JAMA 2015; 314: $1711-1719$.

39 Azoulay E, Lemiale V, Mokart D, et al. Effect of high-flow nasal oxygen $v s$ standard oxygen on 28-day mortality in immunocompromised patients with acute respiratory failure: the HIGH randomized clinical trial. JAMA 2018; 320: 2099-2107.

40 Frat JP, Thille AW, Mercat A, et al. High-flow oxygen through nasal cannula in acute hypoxemic respiratory failure. N Engl J Med 2015; 372: 2185-2196.

41 Frat JP, Ragot S, Girault C, et al. Effect of non-invasive oxygenation strategies in immunocompromised patients with severe acute respiratory failure: a post-hoc analysis of a randomised trial. Lancet Respir Med 2016; 4: 646-652.

42 Mauri T, Spinelli E, Mariani M, et al. Nasal high flow delivered within the helmet: a new non-invasive respiratory support. Am J Respir Crit Care Med 2019; 199: 115-117. 